\title{
Higher or Lower Hemoglobin Transfusion Thresholds for Preterm Infants
}

\author{
H. Kirpalani, E.F. Bell, S.R. Hintz, S. Tan, B. Schmidt, A.S. Chaudhary, K.J. Johnson, M.M. \\ Crawford, J.E. Newman, B.R. Vohr, W.A. Carlo, C.T. D’Angio, K.A. Kennedy, R.K. Ohls, B.B. \\ Poindexter, K. Schibler, R.K. Whyte, J.A. Widness, J.A.F. Zupancic, M.H. Wyckoff, W.E. \\ Truog, M.C. Walsh, V.Y. Chock, A.R. Laptook, G.M. Sokol, B.A. Yoder, R.M. Patel, C.M. \\ Cotten, M.F. Carmen, U. Devaskar, S. Chawla, R. Seabrook, R.D. Higgins, A. Das, Eunice \\ Kennedy Shriver NICHD Neonatal Research Network ${ }^{*}$
}

Department of Pediatrics, University of Pennsylvania, and Children's Hospital of Philadelphia, Philadelphia (H.K., B.S., A.S.C.); the Department of Pediatrics, University of lowa, lowa City (E.F.B., K.J.J., J.A.W.); the Department of Pediatrics, Division of Neonatal and Developmental Medicine, Stanford University School of Medicine and Lucile Packard Children's Hospital, Palo Alto (S.R.H., V.Y.C.), and the Department of Pediatrics, University of California, Los Angeles, Los Angeles (U.D.) — both in California; the Biostatistics and Epidemiology Division, RTI International, Research Triangle Park (S.T., M.M.C.), and the Department of Pediatrics, Duke University School of Medicine, Durham (C.M.C.) - both in North Carolina; the Biostatistics and Epidemiology Division, RTI International, Rockville (J.E.N., A.D.), and the Eunice Kennedy Shriver National Institute of Child Health and Human Development, National Institutes of Health, Bethesda (R.D.H.) - both in Maryland; the Department of Pediatrics, Women and Infants Hospital, Brown University, Providence, RI (B.R.V., A.R.L.); the Division of Neonatology, University of Alabama at Birmingham, Birmingham (W.A.C.); the University of Rochester School of Medicine and Dentistry, Rochester, NY (C.T.D., M.F.C.); the Department of Pediatrics, McGovern Medical School at the University of Texas Health Science Center at Houston, Houston (K.A.K.), and the Department of Pediatrics, University of Texas Southwestern Medical Center, Dallas (M.H.W.); the University of New Mexico Health Sciences Center, Albuquerque (R.K.O.); the Department of Pediatrics, Division of Neonatology, University of Utah School of Medicine, Salt Lake City (R.K.O., B.A.Y.); the Department of Pediatrics, Indiana University School of Medicine, Indianapolis (B.B.P., G.M.S.); Cincinnati Children's Hospital Medical Center, Department of Pediatrics, University of Cincinnati College of Medicine, Cincinnati (B.B.P., K.S.), the Department of Pediatrics, Rainbow Babies and Children's Hospital, Case Western Reserve University, Cleveland (M.C.W.),

\footnotetext{
Address reprint requests to Dr. Kirpalani at the Division of Neonatology, Children's Hospital of Philadelphia, University of Pennsylvania, 34th St. and Civic Center Blvd., Philadelphia PA 19104, or at kirpalanih@email.chop.edu.

The Eunice Kennedy Shriver National Institute of Child Health and Human Development (NICHD) Neonatal Research Network members are listed in the Supplementary Appendix, available with the full text of this article at NEJM.org.

Dr. Carlo reports receiving fees for serving as director from Mednax. No other potential conflict of interest relevant to this article was reported.

The views expressed in this article are those of the authors and do not necessarily represent the official views of the Eunice Kennedy Shriver National Institute of Child Health and Human Development (NICHD), the National Institutes of Health (NIH), the Department of Health and Human Services, or the U.S. government.

Disclosure forms provided by the authors are available with the full text of this article at NEJM.org.

A data sharing statement provided by the authors is available with the full text of this article at NEJM.org.
} 
and Nationwide Children's Hospital and the Department of Pediatrics, Ohio State University College of Medicine, Columbus (R.S.); the Department of Pediatrics, Dalhousie University, Halifax, NS, Canada (R.K.W.); the Department of Neonatology, Harvard Medical School, Beth Israel Deaconess Medical Center, Boston (J.A.F.Z.); the Department of Pediatrics, Children's Mercy Hospital, Kansas City, MO (W.E.T.); Emory University School of Medicine, Department of Pediatrics, Children's Healthcare of Atlanta, Atlanta (R.M.P.); the Department of Pediatrics, Wayne State University, Detroit (S.C.); and the College of Health and Human Services, George Mason University, Fairfax, VA (R.D.H.).

\section{Abstract}

BACKGROUND—Limited data suggest that higher hemoglobin thresholds for red-cell transfusions may reduce the risk of cognitive delay among extremely-low-birth-weight infants with anemia.

METHODS-We performed an open, multicenter trial in which infants with a birth weight of $1000 \mathrm{~g}$ or less and a gestational age between 22 weeks 0 days and 28 weeks 6 days were randomly assigned within 48 hours after delivery to receive red-cell transfusions at higher or lower hemoglobin thresholds until 36 weeks of postmenstrual age or discharge, whichever occurred first. The primary outcome was a composite of death or neurodevelopmental impairment (cognitive delay, cerebral palsy, or hearing or vision loss) at 22 to 26 months of age, corrected for prematurity.

RESULTS-A total of 1824 infants (mean birth weight, $756 \mathrm{~g}$; mean gestational age, 25.9 weeks) underwent randomization. There was a between-group difference of $1.9 \mathrm{~g}$ per deciliter $(19 \mathrm{~g}$ per liter) in the pretransfusion mean hemoglobin levels throughout the treatment period. Primary outcome data were available for 1692 infants $(92.8 \%)$ ). Of 845 infants in the higher-threshold group, $423(50.1 \%)$ died or survived with neurodevelopmental impairment, as compared with 422 of 847 infants (49.8\%) in the lower-threshold group (relative risk adjusted for birth-weight stratum and center, $1.00 ; 95 \%$ confidence interval [CI], 0.92 to $1.10 ; \mathrm{P}=0.93$ ). At 2 years, the higherand lower-threshold groups had similar incidences of death (16.2\% and $15.0 \%$, respectively) and neurodevelopmental impairment (39.6\% and 40.3\%, respectively). At discharge from the hospital, the incidences of survival without severe complications were $28.5 \%$ and $30.9 \%$, respectively. Serious adverse events occurred in $22.7 \%$ and $21.7 \%$, respectively.

CONCLUSIONS-In extremely-low-birth-weight infants, a higher hemoglobin threshold for red-cell transfusion did not improve survival without neurodevelopmental impairment at 22 to 26 months of age, corrected for prematurity. (Funded by the National Heart, Lung, and Blood Institute and others; TOP ClinicalTrials.gov number, NCT01702805.)

Packed red-cell transfusions are commonly used to treat low hemoglobin levels in anemic infants in neonatal intensive care units (NICUs). ${ }^{1}$ Infants with an extremely-low birth weight $(<1000 \mathrm{~g})$ are at high risk for anemia because of immaturity, impaired erythropoiesis, and frequent blood sampling.

Thresholds for transfusion vary ${ }^{2}$ because evidence from randomized trials is limited. ${ }^{3-7}$ The largest trial to inform our trial protocol (available with the full text of this article at NEJM.org) involved more than 450 neonates. That trial showed no difference between 
low and high hemoglobin transfusion thresholds with respect to the primary outcome of clinically significant complications in neonates to 36 weeks of postmenstrual age ${ }^{3}$ or the risk of death or severe adverse neurodevelopmental outcomes at 18 to 21 months of age, corrected for prematurity. ${ }^{6}$ However, a post hoc analysis suggested that the risk of mild-tomoderate cognitive delay was reduced with higher hemoglobin thresholds. ${ }^{6}$

To further examine the effect of transfusion practice on neurodevelopment in extremely-lowbirth-weight infants, we conducted the Transfusion of Prematures (TOP) trial to test the hypothesis that a higher hemoglobin threshold for red-cell transfusions, as compared with a lower threshold, would reduce the incidence of death or neurodevelopmental impairment in infants at 22 to 26 months of age, corrected for prematurity. Both transfusion algorithms used in the trial were consistent with those used in current practice. ${ }^{2}$

\section{METHODS}

\section{TRIAL DESIGN AND OVERSIGHT}

This open, multicenter, randomized, controlled trial was designed by the authors and conducted in 19 centers (41 NICUs) participating in the Neonatal Research Network of the Eunice Kennedy Shriver National Institute of Child Health and Human Development (NICHD), in collaboration with the National Heart, Lung, and Blood Institute (NHLBI). Infants underwent randomization between December 31, 2012, and April 12, 2017, with follow-up through February 3, 2020.

Four of the authors employed by RTI International, the data coordinating center for the Neonatal Research Network, undertook coordination, monitoring, and data collection, storage, management, and analysis. The authors employed by RTI International had full access to all the data in the trial and take responsibility for the integrity of the data and the accuracy of the data analysis. The first five authors and the last author prepared a draft of the manuscript, which was reviewed and approved by the trial subcommittee and all site investigators. The NICHD and NHLBI staff had input into the trial design, conduct, analysis, and drafting of the manuscript. All the authors vouch for the accuracy and completeness of the reporting and for the fidelity of the trial to the trial protocol.

Investigators at each center (listed in Table S1 in the Supplementary Appendix, available at NEJM.org) and RTI International obtained approval of the institutional review board at each participating site and supervised the informed consent process and trial procedures. Written informed consent was obtained from the parent or legal guardian of each child. Independent oversight was provided by the data and safety monitoring committee of the Neonatal Research Network, which included experts in neonatology, bioethics, and biostatistics, as well as a neonatal transfusion specialist appointed for this trial by the NHLBI.

\section{PARTICIPANTS}

Infants with a birth weight of $1000 \mathrm{~g}$ or less, a gestational age between 22 weeks 0 days and 28 weeks 6 days, and a postnatal age of 48 hours or less were eligible to participate in the trial. Infants were excluded if they were considered to be nonviable by the attending neonatologist, had cyanotic congenital heart disease, had parents who were opposed to 
blood transfusion, had a parent with hemoglobinopathy or congenital anemia, had received a transfusion in utero, had twin-to-twin transfusion syndrome or isoimmune hemolytic disease, or had received a previous red-cell transfusion after the first 6 hours of life. Other exclusion criteria were the likelihood that the infant's family would not be able to return for follow-up assessment at 22 to 26 months, receipt or planned receipt of erythropoietin, and a congenital condition (other than premature birth) adversely affecting life expectancy or neurodevelopment.

\section{RANDOMIZATION}

The infants were randomly assigned in a 1:1 ratio to the higher- or lower-threshold group. Randomization was performed centrally by telephone with the data coordinating center. Randomization was stratified according to birth weight ( $<750 \mathrm{~g}$ or 750 to $1000 \mathrm{~g}$ ) and trial center and balanced within randomly chosen block sizes of two or four patients. Multiple-birth siblings underwent randomization individually.

\section{INTERVENTIONS}

All routine red-cell transfusions in both groups were guided by algorithms until the infants reached 36 weeks of postmenstrual age or discharge from the NICU of the trial hospital, whichever occurred first (Table S2). Transfusion algorithms were consistent with current practice, ${ }^{2,8}$ including practice at participating Neonatal Research Network sites. We adhered to ethical recommendations regarding trials of dose-adjusted therapies. ${ }^{9}$ Hemoglobin transfusion thresholds in both groups were determined according to postnatal age (highest in the first week of life, lower in each of the 2 successive weeks, and stable thereafter) and according to the use of respiratory support (a higher threshold when respiratory support was warranted). Respiratory support was defined as mechanical ventilation, continuous positive airway pressure, a fraction of inspired oxygen $\left(\mathrm{FIO}_{2}\right)$ greater than 0.35 , or delivery of oxygen or room air by nasal cannula at a flow of 1 liter per minute or more.

With perfect adherence to these transfusion algorithms throughout the treatment period, the mean between-group difference in the pretransfusion hemoglobin levels was expected to be 2.0 to $2.5 \mathrm{~g}$ per deciliter ( 20 to $25 \mathrm{~g}$ per liter). The transfusion volume was 15 $\mathrm{ml}$ per kilogram of body weight. All transfusions received by the infants were from ABOcompatible and Rh-compatible donors. The clinicians were permitted to deviate from the applicable algorithm temporarily for reasons specified in the protocol (e.g., if the infant had bleeding or anticipated bleeding during or after surgery, severe hypoxemia, hypotension, or sepsis). All the blood transfusions were recorded and centrally reviewed for consistency with the algorithms; if they were inconsistent, they were deemed to be deviations. All deviations were independently adjudicated as being either justified by the protocol or violations according to agreement of two investigators who were unaware of the treatment assignments.

\section{Primary Outcome}

The primary outcome was a composite of death or neurodevelopmental impairment in infants at 22 to 26 months of age, corrected for prematurity. All the follow-up examiners, including psychologists and psychometrists, were unaware of the treatment assignments. 
Neurodevelopmental impairment was defined as one or more of the following components: cognitive delay, moderate or severe cerebral palsy, or severe vision or hearing loss. Cognitive delay was defined as a composite cognitive score of less than 85 (1 SD below the mean of 100) on the Bayley Scales of Infant and Toddler Development, third edition ${ }^{10}$; scores range from 55 to 145, with higher scores indicating better performance. Moderate cerebral palsy was defined as level II or III in the Gross Motor Function Classification System (GMFCS) (levels range from I [mild impairment] to $\mathrm{V}$ [most severe impairment]), and severe cerebral palsy as GMFCS levels IV or V. ${ }^{11}$ Severe vision loss was defined as a corrected visual acuity in the better eye of less than 20/200. Severe hearing impairment was defined as bilateral hearing loss for which hearing aids or cochlear implants were warranted, according to a hearing assessment conducted by sound field testing or according to testing of auditory brain-stem responses. We prespecified that infants without moderate or severe cerebral palsy and without vision or hearing loss had to complete the cognitive subtest of the Bayley Scales successfully in order to be counted as unimpaired for the composite primary outcome.

\section{Secondary Outcomes}

Table S3 lists all the prespecified secondary outcomes to first discharge home and at 2 years of age. Prespecified secondary outcomes at 22 to 26 months of age included death, neurodevelopmental impairment and its four components, and more detailed analyses of the composite cognitive, language, and motor scores on the Bayley Scales. After a protocol change in 2013, the parents or guardians of the infants completed the Child Behavior Checklist ${ }^{12}$ instead of the Brief Infant-Toddler Social and Emotional Assessment in order to comply with revised Neonatal Research Network follow-up procedures.

Prespecified secondary neonatal outcomes included survival to initial hospital discharge without severe complications. These complications included grade 3 or 4 intraventricular hemorrhage, cystic periventricular leukomalacia, or ventriculomegaly diagnosed with the use of clinically performed ultrasonographic examination of the head ${ }^{13}$; stage 3 or greater retinopathy of prematurity or receipt of treatment for that condition ${ }^{14}$; and bronchopulmonary dysplasia diagnosed at 36 weeks of postmenstrual age on the basis of a documented need for supplemental oxygen (defined as an $\mathrm{FIO}_{2}$ of $\geq 0.30$ or inability to pass the oxygen reduction test if the $\mathrm{FiO}_{2}$ was 0.22 to 0.29 ). ${ }^{15}$ Stage 2 or 3 necrotizing enterocolitis was recorded. ${ }^{16}$ The infant's head circumference, weight, and length at a postmenstrual age of 36 weeks, postmenstrual age at the last use of caffeine therapy, and the number of packed red-cell transfusions were also secondary outcomes. For each transfusion, it was noted whether the administration was according to the trial protocol.

\section{STATISTICAL ANALYSIS}

Our main objective was to assess the between-group difference in the composite primary outcome of death or neurodevelopmental impairment at 22 to 26 months of age, corrected for prematurity. On the basis of a previous trial, ${ }^{6}$ we hypothesized that there would be an absolute between-group difference of 7 percentage points in the incidence of death or neurodevelopmental impairment. Given a 52\% incidence of death or neurodevelopmental impairment (unpublished data) in the Neonatal Research Network in 2005-2008 (with entry criteria that were similar to those in this trial), we assumed outcome rates of 53.5\% for 
the lower-threshold group and $46.5 \%$ for the higher-threshold group, centered around a conservative overall event rate of $50 \%$ in the two treatment groups.. We estimated that with a sample of 1824 infants and $10 \%$ loss to follow-up, the trial would have $80 \%$ power to detect an absolute difference of 7 percentage points in the incidence of the primary outcome between the trial groups, at a two-tailed type I error rate of 0.05 .

The independent data and safety monitoring committee reviewed the incoming data at four time points during the enrollment period, as prespecified by the trial protocol. Because primary outcome data were available only at 22 to 26 months of follow-up, statistical interim monitoring at four intervals focused on a composite safety outcome of in-hospital death, necrotizing enterocolitis, or adverse findings on ultrasonographic examination of the head. The significance of the interim safety analyses with O'Brien-Fleming boundaries was calculated with a Lan-DeMets spending function to preserve an overall type I error rate of 0.05 for the composite safety outcome.

All the analyses were adjusted for stratification according to birth-weight group and center, and all the infants were evaluated according to treatment assignment. The primary outcome was analyzed with robust Poisson regression to obtain adjusted relative risks and 95\% confidence intervals. The consistency of the treatment effect across birth-weight strata and sexes and treatment heterogeneity across the various centers were examined by adding suitable interaction terms to the adjusted models. Binary secondary outcomes, including redcell transfusion outcomes, were analyzed with the use of robust Poisson regression. Linear regression was used for the number of transfusions received. Other secondary outcomes, such as the time to regain birth weight and time to full enteral feeding, were analyzed with Cox proportional-hazards survival regression, and data were censored for deaths. There was no prespecified plan to adjust for multiplicity of testing for the secondary outcomes, and a $\mathrm{P}$ value is reported only for the primary outcome (with a two-sided $\mathrm{P}$ value $<0.05$ considered to indicate statistical significance); all the other analyses are exploratory. Analyses were conducted with the use of SAS software, version 9.4 (SAS Institute).

\section{RESULTS \\ PATIENTS}

The composite primary outcome at 22 to 26 months of age could be determined for 1692 of the 1824 infants enrolled (92.8\%). (Fig. 1). Selected characteristics of these infants and their mothers are shown in Table 1, along with those of the entire trial cohort, according to treatment group. All the baseline characteristics of the 911 infants who were randomly assigned to the higher-threshold group were similar to those of the 913 infants who were assigned to the lower-threshold group, and these characteristics were similar in the two groups of infants in the final analysis cohort for the primary outcome. Additional characteristics of the infants are provided in Table S4.

\section{SEPARATION OF THE HEMOGLOBIN LEVELS AND PROTOCOL VIOLATIONS}

At the time of randomization, the mean $( \pm \mathrm{SD})$ hemoglobin levels were similar in the two groups (13.8 $\pm 2.6 \mathrm{~g}$ per deciliter in the higher-threshold group and $13.7 \pm 2.6 \mathrm{~g}$ per deciliter 
in the lower-threshold group) (Table 1). Subsequently, the pretransfusion mean hemoglobin levels differed between the groups by $1.9 \mathrm{~g}$ per deciliter ( $19 \mathrm{~g}$ per liter) throughout the treatment period $(\mathrm{P}<0.001)$ (Fig. $2 \mathrm{~A})$. A comparison of all hemoglobin levels obtained throughout the infants' hospital stay confirmed separation between the mean hemoglobin levels in the two groups (Fig. 2B). Of all red-cell transfusions, 3.5\% were adjudicated to be protocol violations, and $2.5 \%$ of all the transfusions mandated by the respective transfusion algorithms were not administered (Table S5).

\section{PRIMARY OUTCOME}

Complete data for the primary outcome were available for 1692 of 1824 infants (92.8\%). Of the 845 infants with data for this outcome who were assigned to the higher transfusion threshold, 423 (50.1\%) died or survived with impairment, as compared with 422 of 847 infants (49.8\%) assigned to the lower transfusion threshold (adjusted relative risk, 1.00; 95\% confidence interval $[\mathrm{CI}], 0.92$ to $1.10 ; \mathrm{P}=0.93)$. Similar results were obtained in a post hoc sensitivity analysis in which a generalized estimating equation was used to account for any correlation among siblings of a multiple birth (adjusted relative risk, 1.01; 95\% CI, 0.92 to $1.10 ; \mathrm{P}=0.88$ ). The incidences of all components of the primary outcome were similar in the two groups (Table 2).

In addition, there was no evidence that the effects of the transfusion strategy on the primary outcome differed according to center, birth-weight group, or sex (Fig. S1). In sensitivity analyses accounting for missing primary outcome data, the results were materially unchanged, regardless of whether all missing outcomes were assumed to be events (adjusted relative risk, $1.01 ; 95 \% \mathrm{CI}, 0.93$ to 1.09 ) or non-events (adjusted relative risk, 1.00; 95\% CI, 0.91 to 1.10$)$.

\section{SECONDARY OUTCOMES}

The incidences of prespecified short-term and long-term secondary outcomes were similar among infants in the higher-threshold group and those in the lower-threshold group (Table 3 ). The mean $( \pm \mathrm{SD})$ number of transfusions was $6.2 \pm 4.3$ and $4.4 \pm 4.0$, respectively (mean difference, 1.71; $95 \%$ CI, 1.37 to 2.05) (Table 3). A total of 885 of 911 infants (97.1\%) in the higher-threshold group and 804 of 913 infants (88.1\%) in the lower-threshold group received at least one transfusion (adjusted relative risk, 1.10; 95\% CI, 1.08 to 1.13). Additional transfusion data are provided in Table S6. Results for other prespecified and post hoc secondary outcomes are provided in Tables S7 and S8. Serious adverse events occurred in $22.7 \%$ of the infants in the higher-threshold group and $21.7 \%$ of those in the lower-threshold group (adjusted relative risk, 1.04; 95\% CI, 0.88 to 1.23) (Table S9).

\section{DISCUSSION}

Our trial showed that among extremely-low-birth-weight infants, the risk of death or neurodevelopmental impairment at 22 to 26 months of age, corrected for prematurity, was not significantly lower with a higher hemoglobin transfusion threshold level than with a lower hemoglobin transfusion threshold level during the initial hospital course. Although a post hoc analysis of a previous trial had suggested a moderate cognitive benefit at 18 to 
21 months of age in infants who were randomly assigned to maintain a higher hemoglobin level, ${ }^{6}$ the current, much larger trial showed no evidence to support an improvement in this or other components of the composite primary outcome or in any other clinically important outcome, whether measured during the initial hospital course or at 22 to 26 months of age. These results are consistent with the failure of erythropoietin to improve cognitive or other neurodevelopmental outcomes despite increasing red-cell mass. ${ }^{18}$ Our findings are consistent with the results of a similar but smaller European trial that were published while our manuscript was under review. ${ }^{19}$

Although strategies to individualize red-cell transfusions with the use of physiological measures are promising, further testing is needed. ${ }^{20}$ Correspondingly, the use of blood transfusion in NICUs remains high. A Canada-wide study conducted in 2010-2012 showed that $82 \%$ of infants with a birth weight between 501 and $750 \mathrm{~g}$ received red-cell transfusions. ${ }^{21}$ As in our trial, several groups in Europe ${ }^{22}$ and North America ${ }^{23}$ have shown that the use of transfusions decreases when a strict guideline is adopted. In the intervention in the current trial algorithm, we chose hemoglobin levels that would remain within clinically accepted ranges. ${ }^{2,8,9}$

Previous observational data on preterm infants have suggested risks associated with blood transfusions. A large observational cohort study in Brazil involving very-low-birth-weight infants showed an excess cumulative hazard ratio for death in those who received blood transfusions, ${ }^{24}$ but this observation may have been explained by the increased severity of illness in these infants. ${ }^{25}$ Some observational studies have shown an association between transfusions and necrotizing enterocolitis, but observational data have been inconsistent, and this finding has not been supported by available data from randomized trials. ${ }^{26-30}$ One prospective study showed that necrotizing enterocolitis was not associated with transfusion and was more likely to occur when nadir hemoglobin levels decreased to below $8 \mathrm{~g}$ per deciliter ( $80 \mathrm{~g}$ per liter) before transfusion. ${ }^{30}$ In other observational studies, transfusions have been linked to retinopathy of prematurity, ${ }^{31}$ bronchopulmonary dysplasia, ${ }^{32}$ and intraventricular hemorrhage. ${ }^{33}$ In contrast, other studies have suggested that the risks of hypoxemia and apnea of prematurity are increased among infants who do not receive transfusions. ${ }^{34,35}$ We recorded the postmenstrual age at the last use of caffeine therapy as a proxy for apnea, and the results were similar in the two threshold groups. We found no other effects of transfusions on beneficial or adverse outcomes, including stage 2 or 3 necrotizing enterocolitis. Such discrepancies between associations shown in observational studies and our findings underscore the pitfalls of observational studies. ${ }^{36,37}$ Although our trial was not powered to address these individual adverse outcomes, it was a large trial comparing high transfusion thresholds with low transfusion thresholds in this vulnerable population.

Our trial has some important limitations. Blinding of the trial intervention was not feasible at the bedside. However, follow-up examiners were unaware of the treatment assignments. For ethical reasons, we could not withhold nonalgorithmic transfusions (i.e., those that were not performed according to the randomly assigned transfusion algorithm), so there was an imbalanced violation rate, with more nonalgorithmic transfusions in the lower-threshold group. This imbalance presumably reflected the unease of some physicians with hemoglobin levels in the lower range. Nonetheless, the incidence of violations was low and did 
not preclude good between-group separation in mean hemoglobin levels. Blood banks at different centers did not have uniform practices; it would not have been feasible to manage this pragmatic multicenter trial with the use of a single blood bank. However, this variation is unlikely to have affected outcomes, since randomization was stratified according to center. Moreover, apart from leukoreduction, ${ }^{38}$ other blood-banking practices such as transfusing only fresh red cells ${ }^{39,40}$ have not been shown to have beneficial effects. The usual clinical variation in blood-banking practices enhances the generalizability of our findings.

In our trial, a higher hemoglobin threshold for transfusion was associated with an increase in the number of transfusions administered. However, it did not improve survival without neurodevelopmental impairment at 22 to 26 months of age among extremely-low-birthweight infants.

\section{Supplementary Material}

Refer to Web version on PubMed Central for supplementary material.

\section{Acknowledgments}

Supported by grants (U01 HL112776 and U01 HL112748, to Drs. Kirpalani, Bell, and Das) from the National Heart, Lung, and Blood Institute (NHLBI), grants (UG1 HD068244, UG1 HD053109, and U24 HD095254, to the Neonatal Research Network site investigators) from the NICHD, and grant support through cooperative agreements from the NIH, the NICHD, the NHBLI, the National Center for Research Resources, and the National Center for Advancing Translational Sciences.

We thank our medical and nursing colleagues and the infants and their parents and guardians who agreed to take part in this trial, as well as Dr. Traci Mondoro of the NHLBI for her support throughout this trial.

\section{APPENDIX}

The authors' full names and academic degrees are as follows: Haresh Kirpalani, B.M., Edward F. Bell, M.D., Susan R. Hintz, M.D., Sylvia Tan, M.S., Barbara Schmidt, M.D., Aasma S. Chaudhary, B.S., R.R.T., Karen J. Johnson, R.N., B.S.N., Margaret M. Crawford, B.S., C.C.R.P., Jamie E. Newman, Ph.D., M.P.H., Betty R. Vohr, M.D., Waldemar A. Carlo, M.D., Carl T. D’Angio, M.D., Kathleen A. Kennedy, M.D., M.P.H., Robin K. Ohls, M.D., Brenda B. Poindexter, M.D., Kurt Schibler, M.D., Robin K. Whyte, M.B., B.S., John A. Widness, M.D., John A.F. Zupancic, M.D., Sc.D., Myra H. Wyckoff, M.D., William E. Truog, M.D., Michele C. Walsh, M.D., Valerie Y. Chock, M.D., Abbot R. Laptook, M.D., Gregory M. Sokol, M.D., Bradley A. Yoder, M.D., Ravi M. Patel, M.D., C. Michael Cotten, M.D., M.H.S., Melissa F. Carmen, M.D., Uday Devaskar, M.D., Sanjay Chawla, M.D., Ruth Seabrook, M.D., Rosemary D. Higgins, M.D., and Abhik Das, Ph.D.

The authors' affiliations are as follows: the Department of Pediatrics, University of Pennsylvania, and Children's Hospital of Philadelphia, Philadelphia (H.K., B.S., A.S.C.); the Department of Pediatrics, University of Iowa, Iowa City (E.F.B., K.J.J., J.A.W.); the Department of Pediatrics, Division of Neonatal and Developmental Medicine, Stanford University School of Medicine and Lucile Packard Children's Hospital, Palo Alto (S.R.H., V.Y.C.), and the Department of Pediatrics, University of California, Los Angeles, Los Angeles (U.D.) — both in California; the Biostatistics and Epidemiology Division, RTI 
International, Research Triangle Park (S.T., M.M.C.), and the Department of Pediatrics, Duke University School of Medicine, Durham (C.M.C.) - both in North Carolina; the Biostatistics and Epidemiology Division, RTI International, Rockville (J.E.N., A.D.), and the Eunice Kennedy Shriver National Institute of Child Health and Human Development, National Institutes of Health, Bethesda (R.D.H.) - both in Maryland; the Department of Pediatrics, Women and Infants Hospital, Brown University, Providence, RI (B.R.V., A.R.L.); the Division of Neonatology, University of Alabama at Birmingham, Birmingham (W.A.C.); the University of Rochester School of Medicine and Dentistry, Rochester, NY (C.T.D., M.F.C.); the Department of Pediatrics, McGovern Medical School at the University of Texas Health Science Center at Houston, Houston (K.A.K.), and the Department of Pediatrics, University of Texas Southwestern Medical Center, Dallas (M.H.W.); the University of New Mexico Health Sciences Center, Albuquerque (R.K.O.); the Department of Pediatrics, Division of Neonatology, University of Utah School of Medicine, Salt Lake City (R.K.O., B.A.Y.); the Department of Pediatrics, Indiana University School of Medicine, Indianapolis (B.B.P., G.M.S.); Cincinnati Children's Hospital Medical Center, Department of Pediatrics, University of Cincinnati College of Medicine, Cincinnati (B.B.P., K.S.), the Department of Pediatrics, Rainbow Babies and Children's Hospital, Case Western Reserve University, Cleveland (M.C.W.), and Nationwide Children's Hospital and the Department of Pediatrics, Ohio State University College of Medicine, Columbus (R.S.); the Department of Pediatrics, Dalhousie University, Halifax, NS, Canada (R.K.W.); the Department of Neonatology, Harvard Medical School, Beth Israel Deaconess Medical Center, Boston (J.A.F.Z.); the Department of Pediatrics, Children's Mercy Hospital, Kansas City, MO (W.E.T.); Emory University School of Medicine, Department of Pediatrics, Children's Healthcare of Atlanta, Atlanta (R.M.P.); the Department of Pediatrics, Wayne State University, Detroit (S.C.); and the College of Health and Human Services, George Mason University, Fairfax, VA (R.D.H.).

\section{REFERENCES}

1. Patel RM, Meyer EK, Widness JA. Research opportunities to improve neonatal red blood cell transfusion. Transfus Med Rev2016; 30: 165-73. [PubMed: 27424006]

2. Guillén U, Cummings JJ, Bell EF, et al. International survey of transfusion practices for extremely premature infants. Semin Perinatol2012; 36: 244-7. [PubMed: 22818544]

3. Kirpalani H, Whyte RK, Andersen C, et al. The Premature Infants in Need of Transfusion (PINT) study: a randomized, controlled trial of a restrictive (low) versus liberal (high) transfusion threshold for extremely low birth weight infants. J Pediatr2006; 149: 301-7. [PubMed: 16939737]

4. Bell EF, Strauss RG, Widness JA, et al. Randomized trial of liberal versus restrictive guidelines for red blood cell transfusion in preterm infants. Pediatrics2005; 115: 1685-91. [PubMed: 15930233]

5. Whyte R, Kirpalani H. Low versus high haemoglobin concentration threshold for blood transfusion for preventing morbidity and mortality in very low birth weight infants. Cochrane Database Syst Rev2011; 11: CD000512.

6. Whyte RK, Kirpalani H, Asztalos EV, et al. Neurodevelopmental outcome of extremely low birth weight infants randomly assigned to restrictive or liberal hemoglobin thresholds for blood transfusion. Pediatrics2009; 123: 207-13. [PubMed: 19117884]

7. Nopoulos PC, Conrad AL, Bell EF, et al. Long-term outcome of brain structure in premature infants: effects of liberal vs restricted red blood cell transfusions. Arch Pediatr Adolesc Med2011; 165: 443-50. [PubMed: 21199970]

8. Fetus and Newborn Committee, Canadian Paediatric Society. Guidelines for transfusion of erythrocytes to neonates and premature infants. CMAJ1992; 147: 1781-92. [PubMed: 1458420] 
9. Mann H. Controversial choice of a control intervention in a trial of ventilator therapy in ARDS: standard of care arguments in a randomised controlled trial. J Med Ethics2005; 31: 548-53. [PubMed: 16131559]

10. Bayley N. Bayley scales of infant and toddler development. 3rd ed.San Antonio, TX: Harcourt Assessments, 2006.

11. Palisano RJ, Cameron D, Rosenbaum PL, Walter SD, Russell D. Stability of the Gross Motor Function Classification System. Dev Med Child Neurol2006; 48: 424-8. [PubMed: 16700931]

12. Achenbach TM, Rescorla LA. Manual for the ASEBA preschool forms \& profiles. Burlington: University of Vermont, Research Center for Children, Youth, \& Families, 2001.

13. Papile LA, Burstein J, Burstein R, Koffler H. Incidence and evolution of sub-ependymal and intraventricular hemorrhage: a study of infants with birth weights less than 1,500 gm. $\mathrm{J}$ Pediatr1978; 92: 529-34. [PubMed: 305471]

14. International Committee for the Classification of Retinopathy of Prematurity. The International Classification of Retinopathy of Prematurity revisited. Arch Ophthalmol2005; 123: 991-9. [PubMed: 16009843]

15. Walsh MC, Wilson-Costello D, Zadell A, Newman N, Fanaroff A. Safety, reliability, and validity of a physiologic definition of bronchopulmonary dysplasia. J Perinatol2003; 23: 451-6. [PubMed: 13679930]

16. Bell MJ, Ternberg JL, Feigin RD, et al. Neonatal necrotizing enterocolitis: therapeutic decisions based upon clinical staging. Ann Surg 1978; 187: 1-7. [PubMed: 413500]

17. Olsen IE, Groveman SA, Lawson ML, Clark RH, Zemel BS. New intrauterine growth curves based on United States data. Pediatrics2010; 125: e214-e224. [PubMed: 20100760]

18. Juul SE, Comstock BA, Wadhawan R, et al. A randomized trial of erythropoietin for neuroprotection in preterm infants. N Engl J Med2020; 382: 233-43. [PubMed: 31940698]

19. Franz AR, Engel C, Bassler D, et al. Effects of liberal vs restrictive transfusion thresholds on survival and neurocognitive outcomes in extremely low-birth-weight infants: the ETTNO randomized clinical trial. JAMA2020; 324: 560-70. [PubMed: 32780138]

20. Andersen CC, Hodyl NA, Kirpalani HM, Stark MJ. A theoretical and practical approach to defining "adequate oxygenation" in the preterm newborn. Pediatrics2017; 139(4): e20161117. [PubMed: 28325811]

21. Keir AK, Yang J, Harrison A, Pelausa E, Shah PS. Temporal changes in blood product usage in preterm neonates born at less than 30 weeks' gestation in Canada. Transfusion2015; 55: 1340-6. [PubMed: 25652740]

22. Maier RF, Sonntag J, Walka MM, Liu G, Metze BC, Obladen M. Changing practices of red blood cell transfusions in infants with birth weights less than 1000 g. J Pediatr2000; 136: 220-4. [PubMed: 10657829]

23. Widness JA, Seward VJ, Kromer IJ, Burmeister LF, Bell EF, Strauss RG. Changing patterns of red blood cell transfusion in very low birth weight infants. J Pediatr1996; 129: 680-7. [PubMed: 8917234]

24. Nunes dos Santos AM, Guinsburg R, de Almeida MF, et al. Red blood cell transfusions are independently associated with intra-hospital mortality in very low birth weight preterm infants. J Pediatr2011; 159(3): 371-376.e1. [PubMed: 21489555]

25. Kirpalani H, Whyte R. Truths, associations, and hypotheses. J Pediatr2011; 159: 359-61. [PubMed: 21679967]

26. McGrady GA, Rettig PJ, Istre GR, Jason JM, Holman RC, Evatt BL. An outbreak of necrotizing enterocolitis: association with transfusions of packed red blood cells. Am J Epidemiol1987; 126: 1165-72. [PubMed: 3687923]

27. Kirpalani H, Zupancic JA. Do transfusions cause necrotizing enterocolitis? The complementary role of randomized trials and observational studies. Semin Perinatol2012; 36: 269-76. [PubMed: 22818547]

28. Mohamed A, Shah PS. Transfusion associated necrotizing enterocolitis: a meta-analysis of observational data. Pediatrics2012; 129: 529-40. [PubMed: 22351894] 
29. Hay S, Zupancic JA, Flannery DD, Kirpalani H, Dukhovny D. Should we believe in transfusionassociated enterocolitis? Applying a GRADE to the literature. Semin Perinatol2017; 41: 80-91. [PubMed: 27866662]

30. Patel RM, Knezevic A, Shenvi N, et al. Association of red blood cell transfusion, anemia, and necrotizing enterocolitis in very low-birth-weight infants. JAMA2016; 315: 889-97. [PubMed: 26934258]

31. Slidsborg C, Jensen A, Forman JL, et al. Neonatal risk factors for treatment-demanding retinopathy of prematurity: a Danish national study. Ophthalmology2016; 123: 796-803. [PubMed: 26854038]

32. Cooke RW, Drury JA, Yoxall CW, James C. Blood transfusion and chronic lung disease in preterm infants. Eur J Pediatr1997; 156: 47-50. [PubMed: 9007491]

33. Christensen RD, Baer VL, Lambert DK, Ilstrup SJ, Eggert LD, Henry E. Association, among very-low-birthweight neonates, between red blood cell transfusions in the week after birth and severe intraventricular hemorrhage. Transfusion2014; 54: 104-8. [PubMed: 23672455]

34. Zagol K, Lake DE, Vergales B, et al. Anemia, apnea of prematurity, and blood transfusions. J Pediatr2012;161(3): 417-421.e1. [PubMed: 22494873]

35. Abu Jawdeh EG, Martin RJ, Dick TE, Walsh MC, Di Fiore JM. The effect of red blood cell transfusion on intermittent hypoxemia in ELBW infants. J Perinatol2014; 34: 921-5. [PubMed: 24921411]

36. Collins R, Bowman L, Landray M, Peto R. The magic of randomization versus the myth of real-world evidence. N Engl J Med2020; 382: 674-8. [PubMed: 32053307]

37. Silverman WA. Retrolental fibroplasia: a modern parable. New York: Grune \& Stratton, 1980.

38. Fergusson D, Hébert PC, Lee SK, et al. Clinical outcomes following institution of universal leukoreduction of blood transfusions for premature infants. JAMA2003; 289: 1950-6. [PubMed: 12697797]

39. Fergusson DA, Hébert P, Hogan DL, et al. Effect of fresh red blood cell transfusions on clinical outcomes in premature, very low-birth-weight infants: the ARIPI randomized trial. JAMA2012; 308: 1443-51. [PubMed: 23045213]

40. Spinella PC, Tucci M, Fergusson DA, et al. Effect of fresh vs standard-issue red blood cell transfusions on multiple organ dysfunction syndrome in critically ill pediatric patients: a randomized clinical trial. JAMA2019; 322: 2179-90. [PubMed: 31821429] 


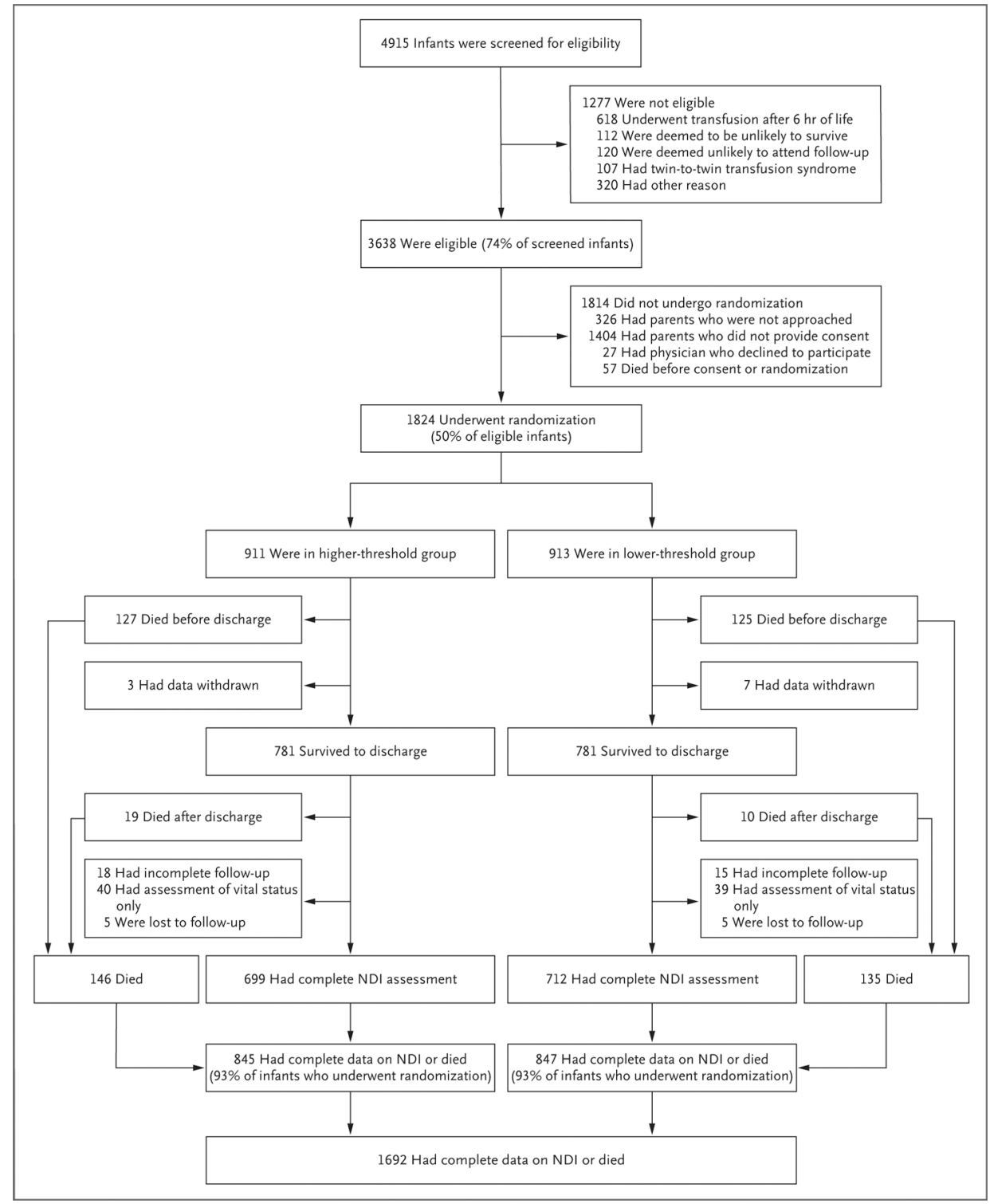

Figure 1 (facing page). Screening, Randomization, Intervention, and Follow-up.

Infants were screened for eligibility only if they met the inclusion criteria of a birth weight of $1000 \mathrm{~g}$ or less, a gestational age between 22 weeks 0 days and 28 weeks 6 days, admission to the center neonatal intensive care unit within 48 hours after birth, and the ability to undergo randomization within 48 hours after birth. The assigned intervention was to extend until 36 weeks of postmenstrual age, unless the infant had been transferred or discharged before that age. In the higher-threshold group, 591 infants completed the treatment per protocol up to 36 weeks, and an additional 137 did so with one or more protocol violations, whereas 183 discontinued treatment early because of death, withdrawal, or transfer or discharge. In the lower-threshold group, 562 infants completed the treatment per protocol up to 36 weeks, an additional 186 did so with one or more protocol violations, and 165 discontinued treatment before 36 weeks. In the higher-threshold group, 23 infants withdrew from the intervention early, of whom 3 had parents who did not consent to their 
inclusion in subsequent analyses. In the lower-threshold group, 16 infants withdrew from the intervention early, of whom 7 had parents who did not consent to their inclusion in subsequent analyses. Two infants who died before 36 weeks of postmenstrual age also withdrew, but in this figure they were counted as infants who died. Infants with incomplete follow-up included those who presented for the follow-up examination but were missing a key component, usually the cognitive subtest of the Bayley Scales of Infant and Toddler Development assessment (14 infants in the higher-threshold group and 8 infants in the lower-threshold group), and those who did not present for examination but had parents who provided limited questionnaire data (4 and 7 infants, respectively). NDI denotes neurodevelopmental impairment. 


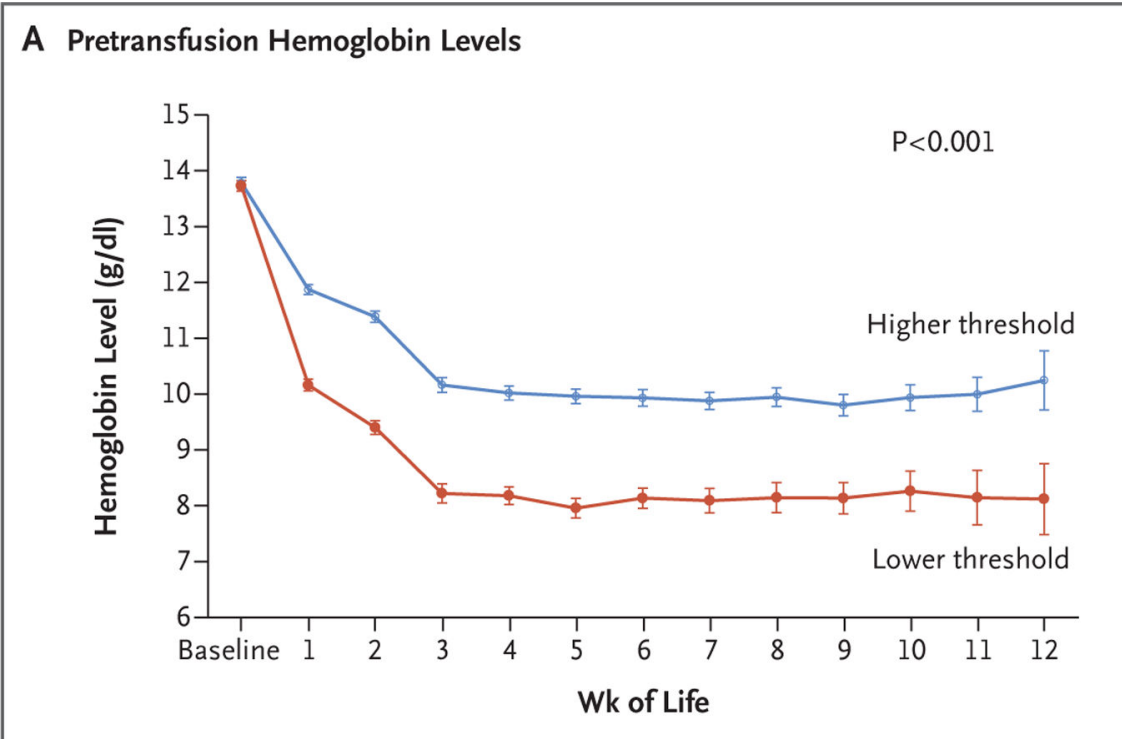

B All Measured Hemoglobin Levels to 36 Wk of Postmenstrual Age

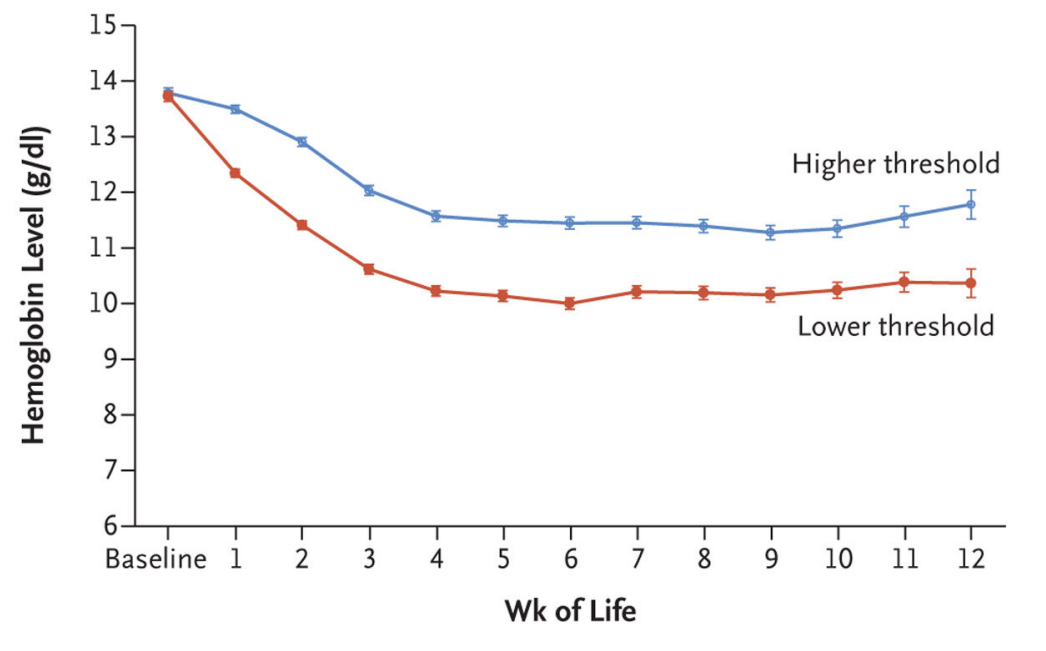

Figure 2. Separation of Hemoglobin Levels between the Treatment Groups.

Hemoglobin levels in the higher-threshold and lower-threshold groups were recorded before enrollment and until 36 weeks of postmenstrual age. Values are means and 95\% confidence intervals (indicated by I bars), adjusted for infant as a random effect. Hemoglobin tests were performed at clinical discretion and were not dictated by protocol. Panel A shows the hemoglobin levels that prompted a red-cell transfusion. Panel B shows all hemoglobin levels that were measured in the two groups during the treatment period. 


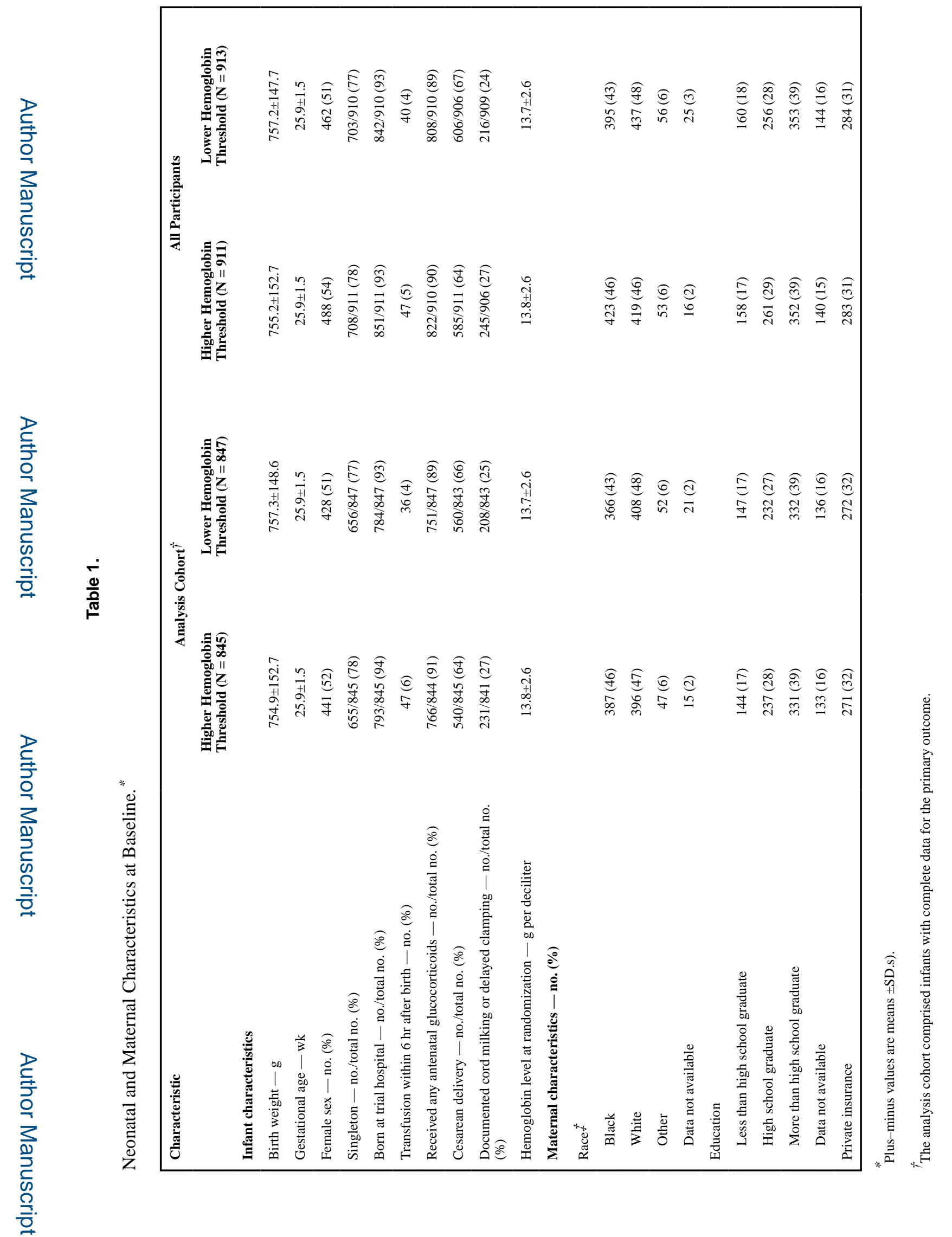

N Engl J Med. Author manuscript; available in PMC 2021 October 03. 

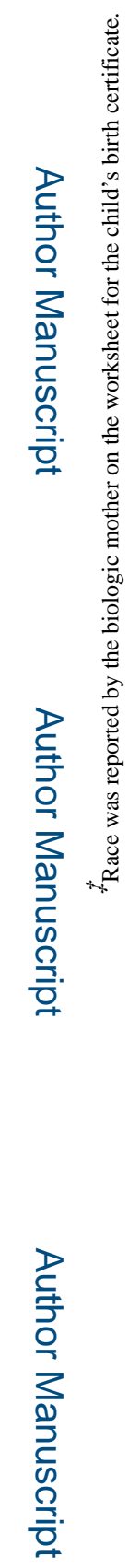

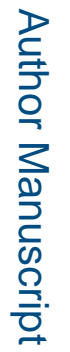

N Engl J Med. Author manuscript; available in PMC 2021 October 03. 


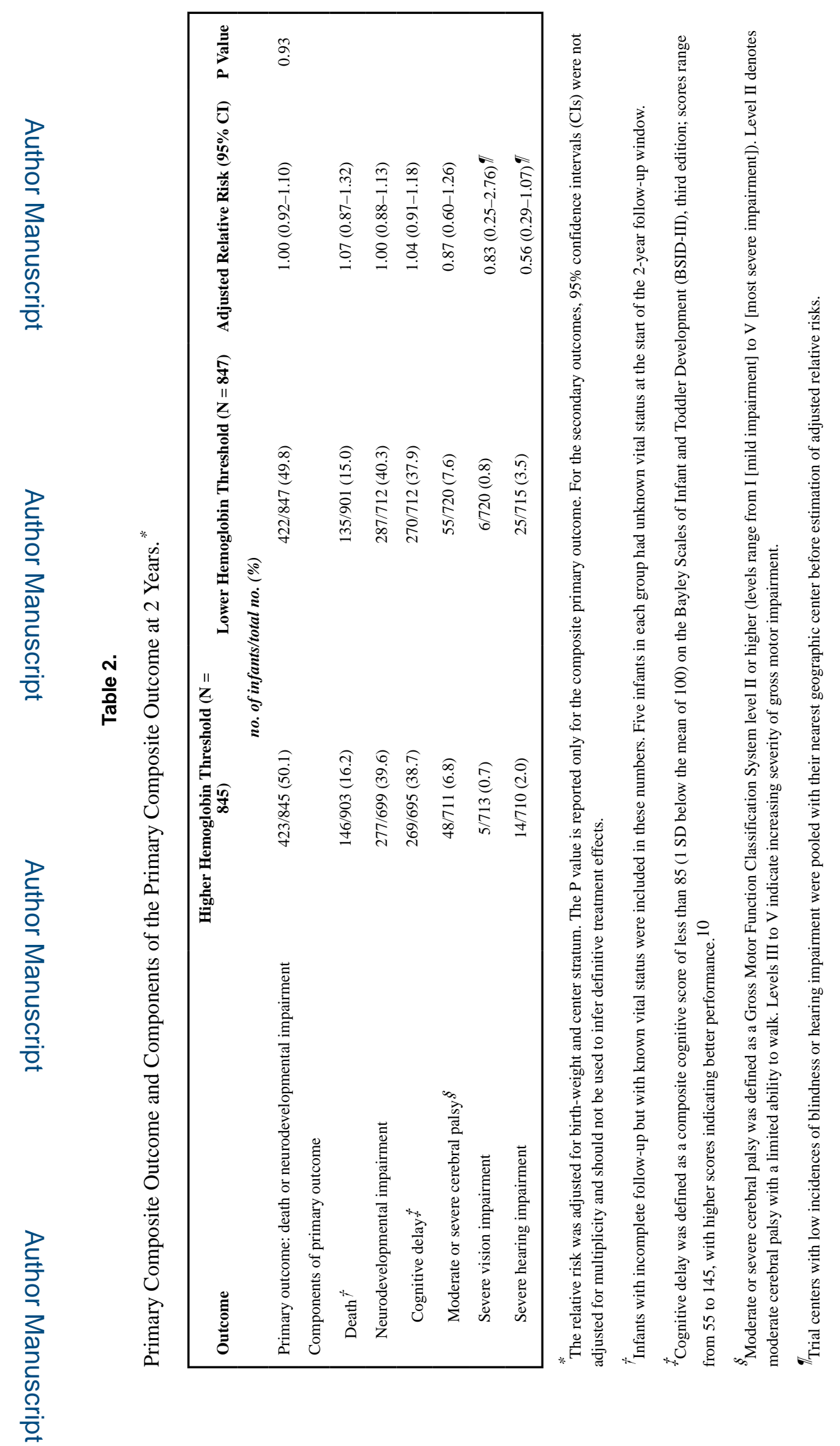

NEngl J Med. Author manuscript; available in PMC 2021 October 03. 


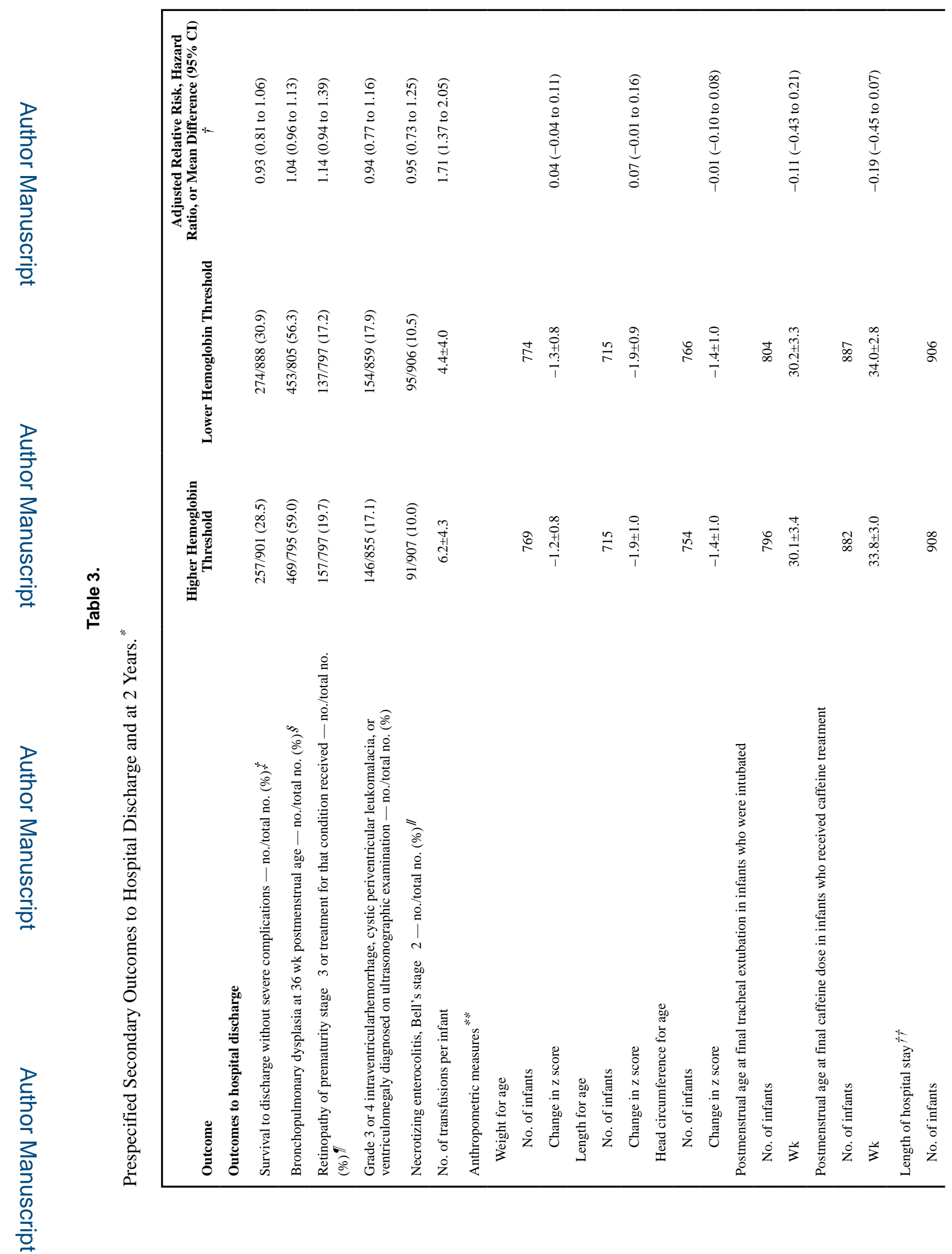

NEngl J Med. Author manuscript; available in PMC 2021 October 03. 


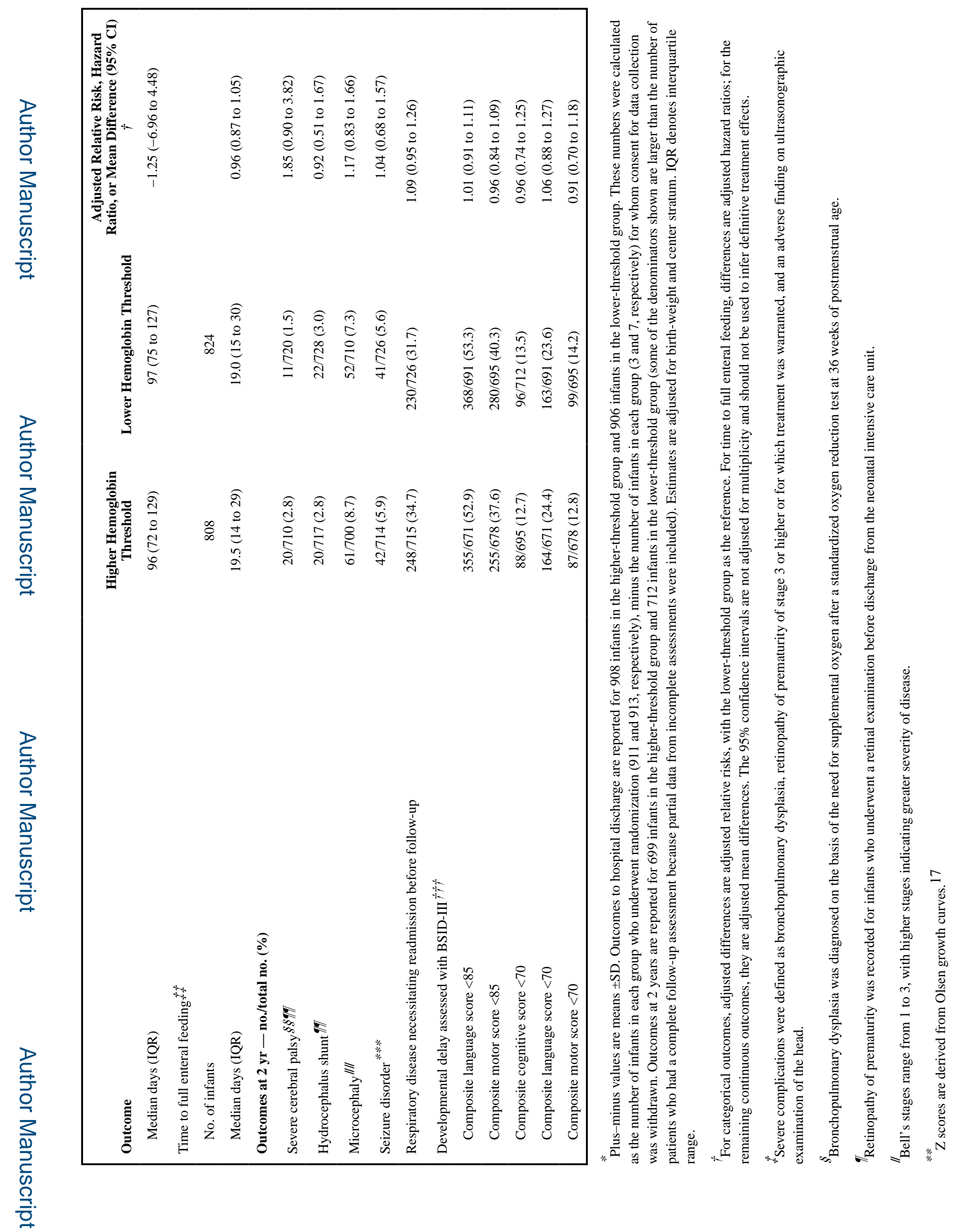

NEngl J Med. Author manuscript; available in PMC 2021 October 03. 


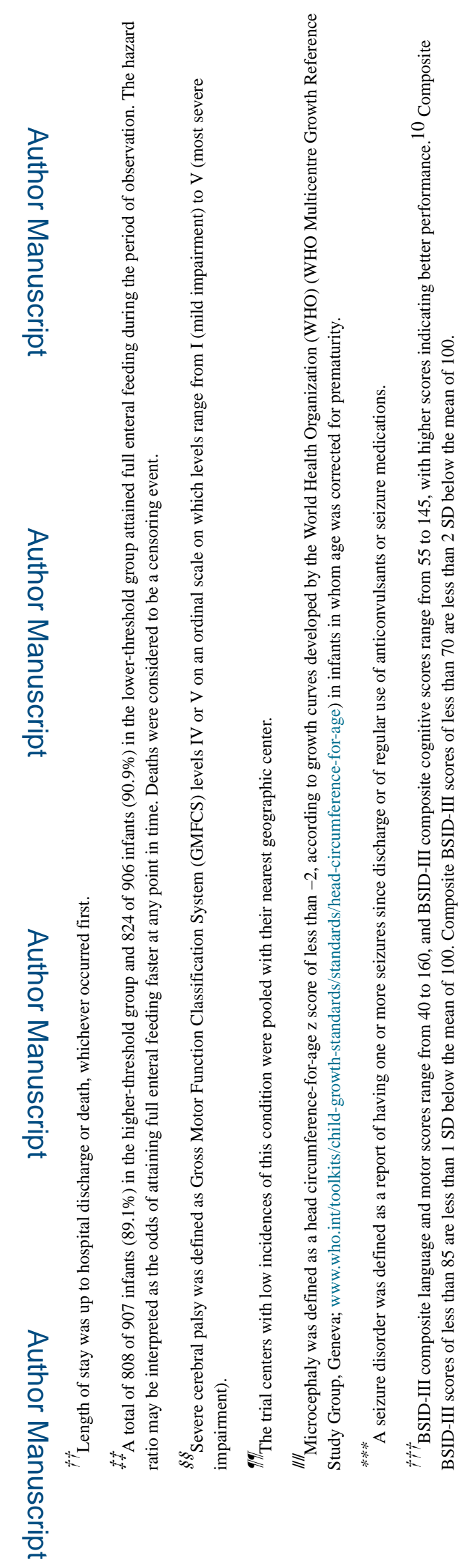

NEngl J Med. Author manuscript; available in PMC 2021 October 03. 